\title{
Comparison of postoperative analgesic efficacy of preemptive USG-guided TAP block, USG-guided local infiltration and intravenous dexketoprofen in inguinal hernia repair
}

Fikret Salık ( $\square$ fikretsalik@gmail.com )

Gazi Yaşargil Training and Research Hospital https://orcid.org/0000-0002-7715-3545

Mustafa Bıçak

Gazi Yaşargil Training and Research Hospiatl

Hakan Akelma

Gazi Yaşargil Training and Research Hospital

\section{Research article}

Keywords: Inguinal hernia repair; preemptive analgesia; transversus abdominis plane block; intravenous dexketoprofen.

Posted Date: January 20th, 2020

DOI: https://doi.org/10.21203/rs.2.21358/v1

License: (c) (1) This work is licensed under a Creative Commons Attribution 4.0 International License.

Read Full License 


\section{Abstract}

Background Although regional techniques have been suggested more in order to provide postoperative analgesia in inguinal hernia repairs, the ideal method is still controversial. The aim of this study was to evaluate the effect of preemptive transversus abdominis plane (TAP) block, local anesthetic infiltration (LAI) and intravenous dexketoprofen (IVD) on postoperative pain in inguinal hernia repairs. Methods This prospective study included 120 patients with American Society of Anesthesiologists status 1-3 between 18-75 years of age who undergoing elective inguinal hernia surgery under spinal anesthesia. The patients were allocated into three groups: USG-guided TAP block (Group 1, n = 40), USG-guided LAI (Group 2, n = 40 ) and IVD (Group 3, $n=40$ ) before surgical incision. The mean of tramadol consumption, number of patients in requiring rescue analgesics, duration of postoperative analgesia and complications were recorded for 24 hours postoperatively. VAS scores were evaluated at the 30 minute, 1, 2, 4, 8, 12, 16 and 24th hours. Results There was no significant difference between the postoperative mean tramadol consumption [Group 1: $22.5 \mathrm{mg}$; Group 2: $20 \mathrm{mg}$; Group 3: 27.5 ( $\mathrm{p}$ 0.833)]. The number of patients requiring rescue analgesics was statistically similar ( $p$ 0.787). VAS scores at 30 . min, 1, 2, 4, 8 and 12 hours were statistically lower in Group 1 than in the other groups ( $0.003,007,0013,0049,0015,0021)$. VAS scores at 30. min and 2. h were lower in Group 1 than Group 2 ( $p$ 0.049, 0.037). In addition, VAS scores at $30 \mathrm{~min}, 1,2,8$ and 12 hours were lower in Group 1 than in Group 3 (p 0.003, 0.006, 0.021, 0.017, 0.016). VAS scores at all hours were statistically similar between Group 2 and Group 3. Conclusion This study demonsrated that preemptive transversus abdominis plane block, local anesthetic infiltration or iv dexketoprofen for postoperative analgesia in inguinal hernia repairs had similar effects on postoperative tramadol consumption and number of requiring rescue analgesic patients. However, TAP block provides lower VAS values and excellent analgesia in more patients in the first 24 hours postoperatively.

\section{Background}

Inguinal hernia repair may cause moderate or severe pain due to abdominal wall incision despite the use of more non-invasive techniques (Lichtenstein technique) today [1, 2]. Although spinal anesthesia provides postoperative analgesia for a certain period of time, after the effect of spinal anesthesia has passed, patients may experience severe pain. If effective postoperative analgesia is not provided, this pain may impair the quality of life by limiting daily activities and causing chronic pain [1-3]. This may increase the length of hospital stay and hospital costs. Therefore, effective postoperative analgesia management may enable the patient to return to his / her daily life early and to reduce health costs [4].

Currently, multimodal techniques are used in inguinal hernia repairs in addition to pharmacological and regional techniques for postoperative analgesia [1]. One of these techniques, transversus abdominis plan (TAP) block, has been used frequently in recent years [5]. TAP block is performed on the principle of hydrodissection of the fascia between the internal oblique and transversus abdominis muscles of the abdominal wall muscles with local anesthetic drugs [6, 7]. Local anesthetic drugs provide analgesic effect up to 24 hours in the postoperative period by blocking the T6-L1 nerves in the facial plane $[5,8]$. Although TAP block was first applied by landmark technique from the point of petite triangle, it has been 
applied in a simple and reliable way with imaging with the use of USG [7]. Local anesthetic infiltration (LAl), which is one of the regional anesthetic techniques, is another method of postoperative analgesia. This procedure is mostly performed to the surgical incision lines by the surgical team [9]. In addition to these two technics, intravenous analgesic drug (IVAD) is also used as pharmacological postoperative analgesia method in most clinics [1, 10]. Nonsteroidal anti-inflammatory drugs (NSAID), paracetamol, cyclooxygenase inhibitors, opioids, glucocorticoids, clonidine, magnesium, gabapentin and pregabalin are used for this purpose $[1,10,11]$. One of these drugs, dexketoprofen, has been used to provide postoperative analgesia in different surgical procedures [12].

There are many studies in which all three methods are used preemptively in inguinal hernia operations [1, 11]. However, despite the use of different types of nsaid in previous studies, we could not find any studies in which intravenous dexketoprofen (IVD) was administered preemptively. We also found no studies comparing TAP block, LAI and IVD for preemptive analgesia.

In this study, we aimed to compare the effects of USG-guided TAP block, local anesthetic infiltration to the incision line and intravenous dexketoprofen on postoperative analgesic efficacy and rescue tramadol consumption in inguinal hernia repairs performed under spinal anesthesia.

\section{Methods}

This prospective and observational study was conducted on 131 patients of the American Society of Anesthesiologist (ASA) I-III aged 18-75 years who undergoing unilateral or bilateral inguinal hernia repair after obtaining the ethical committee approval and written informed consent from the patients at Diyarbakır Gazi Yaşargil Training and Research Hospital. The study was conducted in accordance with the Helsinki II declaration.

Patients under 18 and over 75 years of age, ASA IV, a history of allergy to agents, analgesic drug use in the last 48 hours, morbid obese (BMl> 35), confusion, coagulopathy, local infection at the injection site were excluded from the study. In addition, patients with heart, lung, hematologic, metabolic and endocrine problems were also excluded. Furthermore, patients who did not want to be included in the study, who refused the spinal anesthesia procedure and who failed the spinal anesthesia procedure were excluded. The patients were informed about the procedure and Visual Analogue Scale (VAS, $0=$ no pain, $10=$ severe pain) at the preoperative visit. Postoperative nausea-vomiting (PONV) was evaluated with a 3-point system ( 0 : no nausea and vomiting, 1 : nausea, but no vomiting, 2 : nausea with or without nausea).

Demographic data such as age, gender, height, weight, duration of surgery, postoperative discharge time and postoperative analgesia method were recorded. Patients were allocated into three groups: USGguided TAP block (Group 1), USG-guided LAI (Group 2) and IVD (Group 3).

Standard anesthesia regime was received to all patients. After a preoperative 6-8 hour fasting period, patients were presented to the operation room. Heart rate (HR), non-invasive arterial pressure (NIBP), electrocardiogram (ECG) and peripheral oxygen saturation $\left(\mathrm{SpO}_{2}\right)$ monitoring were performed as 
standard. $0.02 \mathrm{mg} / \mathrm{kg}$ midazolam(Zolamide $5 \mathrm{mg} / 5 \mathrm{ml}$ amp, Vem, Turkey) was administered for premedication to peripheral vascular access. IV saline was initiated at $10-15 \mathrm{ml} / \mathrm{kg}$ and the patient was placed in a sitting position. After sterilization, an experienced anesthesiologist performed a subarachnoid puncture through the $\mathrm{L}_{3-4}$ or $\mathrm{L}_{4-5}$ intervertebral space with a $26 \mathrm{G}$ quincke needle (Egemen, Izmir, Turkey). After cerebrospinal fluid flow was seen, spinal anesthesia was performed with 12-15 mg heavy bupivacaine (Bupivon, Spinal heavy $0.5 \%$, Onfarma, Turkey). The patients were then placed in the supine position. Before surgery, USG-guided TAP block was performed preemptively to Group 1 patients, USGguided LAI to the surgical incision line, and $50 \mathrm{mg}$ IVD was administered to Group 3 patients. When the motor block reached 3 on the Bromage Scale (0: no paralysis, the patient can fully flex the foot and knee; 1: can only move the knee and feet, cannot lift the leg straight, hip flexion is present; 2 : no knee flexion; 3 : complete motor block), and sensorial block reached the level of thoracic 6-8, surgical procedure was allowed. In case of failed spinal anesthesia, general anesthesia was performed and these patients were excluded from the study. Heart rate and NIBP values were recorded every 5 minutes during the operation. Patients with bradycardia and / or hypotension were treated with atropine and / or ephedrine. The study was completed with 120 patients who had failed spinal anesthesia and those who were discharged early from the hospital voluntarily (Figure 1).

\section{TAP Block}

TAP block was performed under USG guidance (Esaote, MyLab Six, Netherlands) before the surgery. After sterilization, the linear USG probe $(5-10 \mathrm{MHz})$ was transversely placed on the mid-axillary line between the iliac crest and costal margine (Figure 2). USG visualised skin-subcutaneous tissue, external oblique, internal oblique and transversus abdominis muscles and peritoneal cavity (Figure 3). A $20 \mathrm{G}$ nerve block needle (Stimuplex Ultra 360, B.Braun, Melsungen, Germany) was imaged with in-plane technique to advance the facial plane between the internal oblique and transverse abdominis muscles. The injection point was confirmed by hypoechoic image with 0.2 to $0.4 \mathrm{~mL}$ of normal saline. Then, $20 \mathrm{~mL} 0.25 \%$ bupivacaine (Buvasin $0.5 \%$, Istanbul, Turkey) was injected to the facial plane by intermittent following negative aspiration by hydrodissection technique (Figure 4). In bilateral cases, the procedure was performed to both sides in the same way. All blocks were performed by a single experienced anesthesiologist.

\section{Local Anesthetic Infiltration}

LAI was performed under USG guidance before the surgical procedure. $20 \mathrm{~mL} 0.25 \%$ bupivacaine was injected after the following negative aspiration with a $20 \mathrm{G}$ nerve block needle into and around the incision line to be pre-marked by the surgeon, and between the incision line and under the aponeurosis external oblique (Figure 5). All LAl were performed by a single experienced anesthesiologist.

\section{Intravenous Dexketoprofen Application}

$50 \mathrm{mg}$ dexketoprofen trometamol (Metadem, $5 \mathrm{mg} / 2 \mathrm{ml}$ amp, Vem, Turkey) was administered to the IVD group before surgery. Patients were given intravenous doses of $50 \mathrm{mg}$ dexketopropophen in repeated 
doses in the postoperative period every 8 hours until discharge.

The patients were taken to the postanesthetic care unit after the operation. All patients received $10 \mathrm{mg} /$ $\mathrm{kg}$ paracetamol iv infusion every 6 hours postoperatively. Postoperative pain severity was evaluated by VAS score. VAS score and nausea and vomiting scores were recorded at 30. $\min , 1,2,4,8,12,16$ and 24 hours postoperatively. Those with a VAS score of 0 had no pain (excellent analgesia) and those with $\leq 3$ were considered mild pain without rescue analgesics. Patients with a VAS score of 4-6 were considered as moderate pain and patients with 7-10 were considered as severe pain. According to the VAS score, iv tramadol was given $400 \mathrm{mg}$ / day maximum every 8 hours if necessary. 24-hour mean VAS scores were calculated.

Number of patients who required rescue analgesic, time of first analgesic requirement, duration of analgesia, mean tramadol consumption, side effects and complications were recorded during the first 24 post-operative hours. Patients with nausea and vomiting were given intravenous $4 \mathrm{mg}$ ondansetron (Kemoset, 8mg / 4ml, Deva, Turkey). After the postoperative follow-up, patients without any problems were discharged.

\section{Statistical Analysis}

G-Power version 3.1.9.4 (Universität Kiel, Germany) was used to calculate the sample size. An alpha error of 0.05 , Power (1- $\beta$ err probe) 0.95 , Numerator df 3 , Number of groups 3 and effect size 0.4 were considered and the minimum number of patients included in the study was calculated as 112 .

SPSS 16.0 for Windows (SPSS Inc., Chicago, IL, USA) was used for statistical analysis. Statistically numerical data mean and standard deviation; categorical data were expressed as frequency and percentage. The comparison of categorical data in the groups was analysed with chi-square test and the results were given as $n \%$. The Kolmogorov-Smirnov test was used to determine whether the numerical data matched the normality distribution. One-way ANOVA test was used to compare the normality distribution and Kruskal-Wallis test was used to compare the non-normality distribution. Post Hoc analysis was used to determine the difference between the groups after sig nificant values. In all comparisons, $p<0.05$ was considered statistically significant.

\section{Results}

131 patients were invetigated during the study. Five patients were excluded due to unsuccessful spinal anesthesia and 6 patients could not adapt to the study (Figure 1). There were no significant differences between the groups in terms of demographic data, surgical region and surgical time (Table 1).

At any of the postoperative hours VAS score was $\leq 3$ (mild pain) and those who were not in need of tramadol were established as 85\% $(n=34)$ in Group 1, 85\% $(n=34)$ in Group $2(n=34)$, and $80 \%$ in Group $3(n=32)$. The rate of patients with a VAS score of $4-6$ (moderate pain) was detected $15 \%(n=6)$ in 
Group 1, $15 \%(n=6)$ in Group 2, and $20 \%(n=8)$ in Group 3. None of the groups had a VAS score of 7-10 (severe pain). There were no statistically significant differences between the groups (Table 2,3).

The mean tramadol consumption in the first 24 hours was 22.5mg in Group 1,20mg in Group 2 and $27.5 \mathrm{mg}$ in Group 3. There were no statistically significant differences between the groups (Table 2).

Postoperative analgesia duration was 21.0 hours in Group 1, 21.20 hours in Group 2 and 21.40 hours in Group 3. There were no statistically significant differences between the groups (Table 2).

Complications were detected 15\% $(n=6)$ in Group 1 and 5\% $(n=2)$ in Group 3, but no complications were detected in Group 2 (Table 2). The complication rate was significantly higher in Group 1 compared to the other groups $(p=0.024)$. One patient in group 1 encourted glob vesical. The bladder was treated with catheter application. All other complications were nausea and treated with $8 \mathrm{mg}$ iv ondansetron.

VAS scores at 30 min, 1, 2, 4, 8 and 12 hours were significantly lower in Group 1 than in the other groups (p $0.003,007,0013,0049,0015,0021)$. Similar results were determined in all groups at 16 th and 24 th hours. The mean 24-hour VAS values were 0.95 in Group 1, 1.32 in Group 2 and 1.57 in Group 3. An additional analysis was performed to compare the groups. VAS scores at $30 \mathrm{~min}$ and $2 \mathrm{~h}$ were significantly lower in Group 1 than Group 2 ( $p 0.049,0.037$ ). There were no significant differences between the two groups in the other hours. At the same time, VAS scores at $30 \mathrm{~min}, 1,2,8$ and 12 hours were lower in Group 1 than in Group 3 ( $p$ 0.003, 0.006, 0.021, 0.017, 0.016) and were similar in other follow-up. There were no significant differences between Group 2 and Group 3 in terms of VAS scores at all hours (Table 4, Figure 6).

There were no significant differences between the groups in terms of sedation scores.

\section{Discussion}

In our prospective observational study, in which we compared preemptive TAP block, local anesthetic infiltration and intravenous dexketoprofen in inguinal hernia operations, we found that postoperative opioid consumption and the number of patients received rescue analgesic were equal. In addition, we demonstrated that VAS scores, a sign of patient comfort, to be similar in local anesthetic infiltration and intravenous dexketoprofen and lower in TAP block than in the other two performs.

It is known that TAP block reduces postoperative opioid consumption, provides early mobilization and increases quality of life [13]. Salman et al. reported that lower opioid consumption in patients who performed TAP block with landmark technique under spinal anesthesia compared to placebo group [14]. However, it has been reported by the investigators that postoperative opioid consumption is lower in patients who performed USG-guided TAP block than those performed LAI [15, 16]. Petersen et al., in contrast to other studies, applied preemptive LAI and TAP block and stated that there was a lower opioid consumption in the LAI group compared to USG-guided TAP block and placebo groups in the first 2 hours postoperatively but there was no significant differences between the groups in the 2-24 hours period [2]. 
When we compared preemptive TAP block and LAl in terms of postoperative opioid consumption, we found that both methods had similar results in contrast to the literature. In addition, our results are similar to the results of Petersen et al. for the 2-24 hours results, while they contradict the first 2-hour period. We believe that this result stems from the fact that it is effective to apply it to the correct location using USG in contrast to false localizations such as subcutaneous or intramuscular local infiltration by blind technique.

In placebo-controlled studies, it has been reported that IVAD administration alone reduces rescue analgesic use $[1,17]$. In studies comparing LAI with NSAID administration, similar results were reported between the groups [1]. In studies comparing only patients who received IVAD and USG-guided TAP block + IVAD, it was found that there was a lower amount of rescue opiod consumption in the TAP block group in the postoperative period $[5,13]$. Although there are comparisons between preemptive IVAD and TAP block or LAI with different drugs in our literature investigation, we could not find any studies comparing these applications with preemptive dexketoprofen. In our study, we found that there was no difference between preemptive iv dexketoprofen and TAP block and LAI in terms of postoperative opioid consumption. As Long et al. stated this result arises from the fact that preemptive IVAD application in preventing the access of central nervous system to afferent pain signals due to surgical trauma is due to sufficient effect as well as other methods [18].

Kendigelen et al. in their study involving 80 patients, $32.5 \%$ of the TAP block group and $100 \%$ of the LAl group reported rescue analgesic requirement in the first 24-hour period [15]. Talip et al., in their study evaluated 100 patients, found the number of patients in need of additional opioid to be $8 \%$ in the USGguided TAP block group and $84 \%$ in the LAl group [16]. Beyoğlu et al. compared IVAD and USG-guided TAP block + IVAD applications and found that fewer patients in the TAP block group needed rescue analgesics in the postoperative period [5]. In our study, we demonsrated that there was no difference between preemptive IVD, TAP block and LAl in terms of the number of patients who needed postoperative rescue analgesic drugs. When we compared TAP block and LAI groups with each other, we found similar results in both groups unlike previous studies. We think that the local anesthetic infiltration to the correct location with USG guidance is effective in achieving this result. Because the LAI procedure performed by blind technique may be injected to wrong localizations such as subcutaneous or intramuscular.

In inguinal hernia operations, in TAP block or local infiltration performed for postoperative analgesia in the postoperative 24-48 hour period the pain scores were found to be lower compared to placebo $[9,19$, 20]. Studies comparing TAP block and LAI or TAP block and conventional systemic analgesia have been reported to have lower mean VAS scores in patients undergoing TAP block $[13,16]$. Joshi et al., in their systematic reviews, reported that similar pain scores in LAl and field blocks, and lower pain scores in LAl while compared to LAI and IVAD [1]. Petersen et al. in their study investigating USG-guided TAP block, LAI and placebo, they found lower VAS scores in the LAI group in the first 6 hours postoperatively [2]. Yücel et al. evaluated preemptive ilioinguinal-iliohipogastric nerve block and block + iv dexketoprofen groups with the control group and found lower VAS scores in the group received dexketoprofen in the first 12 hours postoperatively [21]. In our study, postoperative first 12-hour VAS scores were lower in the TAP block 
group than in the other two groups, and 12-24-hour VAS scores were similar in all groups. When we compared the groups among themselves, in contrast to Petersen et al., the VAS scores at 30 min and $2 \mathrm{~h}$ were lower in the TAP block group compared to the local anesthetic infiltration group, and the VAS scores at the other hours were similar in both performs. In both groups, we demonsrated VAS scores except 30 min and $2 \mathrm{~h}$ similar like Joshi et al. When we compared local anesthetic infiltration and iv dexketoprofen in terms of postoperative VAS scores, we found similar results in both performs unlike Joshi et al. We also found excellent analgesia (VAS $=0$ ) in 10 patients in the TAP block group and 1 patient in the IVD group. As for in the LAl group, no analgesia was encountered in any patient.

In their study with 60 patients who undergoing inguinal hernia operation Theodoraki et al. reported that PONV developed in $17.2 \%$ of the TAP block group and in $30 \%$ of the placebo group [19]. Talib et al. found that PONV rate was $21.7 \%$ in the TAP block group and $78.3 \%$ in the LAl group in their study involving 100 patients [16]. In our study, we detected nausea in $12.5 \%$ of the TAP block group and $5 \%$ in the IVD group, but we found no nausea in the LAI group. We also encountered globe vesical in 1 patient in TAP block group. None of the patients encountered any side effects or complications related to TAP block and local anesthetic infiltration procedures.

\section{Conclusion}

In conclusion; TAP block, local anesthetic infiltration or iv dexketoprofen can be used preemptively for postoperative analgesia in patients undergoing inguinal hernia repair under spinal anesthesia. The effects of these applications on the amount of postoperative opioid consumption and the number of patients in need of rescue analgesic drugs are similar. However, TAP block application has lower VAS values in the first 24 hours and provides excellent analgesia in more patients, shown that TAP block is more effective than other applications in terms of patient comfort. Performing local anesthetic infiltration to the correct location with USG guidance may also improve the quality of postoperative analgesia. However, we think that more detailed and comprehensive studies should be done about preemptive application of these procedures.

\section{The Limitation}

The limitations of our study are the duration of discharge, pain with movement and the fact that chronic pain were not evaluated.

\section{Abbreviations}

TAP: Transversus abdominis plane; LAl: Local anesthetic infiltration; IVD: Intravenous dexketoprofen; ASA: American Society of Anesthesiologists; VAS: Visual Analogue Scale; IVAD: Intravenous analgesic drug; NSAID: Nonsteroidal anti-inflammatory drugs; BMI: Body mass index; PONV: Postoperative nauseavomiting; HR: Heart rate; NIBP: Non-invasive arterial pressure; ECG: Electrocardiogram; $\mathrm{SpO}_{2:}$ Peripheral oxygen saturation 


\section{Declarations}

Ethics approval consent to participate: This study was approved by the Local Ethics Committee University of Health Sciences Gazi Yaşargil Training and Research Hospital. (approval date and number: 08.02.2019-225).

Consent for publication: Not applicable.

Availability of data and material: The datasets used and/or analyzed during the current study are available from the corresponding author on reasonable request.

Competing interests: The authors declare that they have no competing interests.

Funding: None of the authors received funding for contribution to this study.

Authors' contributions: FS initiated and designed the study, and analyzed and interpreted the patient data, and was a major contributor in writing the manuscript. MB designed the study database. HA performed statistical processing and drafting of the manuscript. All authors read and approved the manuscript in its final version.

Acknowledgements: The authors thank the Sedat Kaya for his help in the study.

Author details: ${ }^{1}$ Gazi Yaşargil Training and Research Hospital, Anesthesiology and Reanimation Clinic, Diyarbakir, Turkey

CONSORT: Our study adheres to CONSORT guidelines

\section{References}

1. Joshi GP, Rawal N, Kehlet H. Evidence-based management of postoperative pain in adults undergoing open inguinal hernia surgery. Br J Surg. 2012;99(2):168-85.

2. Petersen PL, Mathiesen O, Stjernholm P, Kristiansen VB, Torup H, Hansen EG, Mitchell AU, Moeller A, Rosenberg $\mathrm{J}$ and Dahl JB. The effect of transversus abdominis plane block or local anaesthetic infiltration in inguinal hernia repair: A randomised clinical trial. Eur J Anaesthesiol. 2013;30(7):41521.

3. Tsai H-C, Yoshida T, Chuang T-Y, Yang S-F, Chang C-C, Yao H-Y, Tai Y-T, Lin J-A, and Chen K-Y. Transversus Abdominis Plane Block: An Updated Review of Anatomy and Techniques. Biomed Res Int. 2017;2017:1-12.

4. Nir RR, Nahman-Averbuch H, Moont R, Sprecher E, Yarnitsky D. Preoperative preemptive drug administration for acute postoperative pain: A systematic review and meta-analysis. Eur J Pain. 2016;20(7):1025-43. 
5. Akyol Beyoğlu C, Ozdilek A, Erbabacan E, Ozmumcu EA, Ekici B, Köksal G, Altıntaş F, Purisa S. Evaluation of the effects of subcostal transversus abdominis plane block on acute and subacute pain development following inguinal herniography: Randomized clinical study. Agri. 2018;30(3):1239.

6. Rafi AN. Abdominal field block via the lumbar triangle revisited. Anaesthesia. 2012;67(12):1399-401.

7. Hebbard P, Fujiwara Y, Shibata Y, Royse C. Ultrasound-guided transversus abdominis plane (TAP) block. Anaesth Intensive Care. 2007;35(4):616-8.

8. McDonnell JG, O'Donnell BD, Farrell T, Gough N, Tuite D, Power C, and Laffey JG. Transversus Abdominis Plane Block: A Cadaveric and Radiological Evaluation. Reg Anesth Pain Med. 2007;32(5):399-404.

9. Dierking GW, Østergaard E, Østergaard HT, Dahl JB. The effects of wound infiltration with bupivacaine versus saline on postoperative pain and opioid requirements after herniorrhaphy. Acta anaesthesiologica scandinavica. 1994;38(3):289-92.

10. Englbrecht JS, Pogatzki-Zahn EM. Perioperative schmerztherapie bei abdominellen und thorakalen operationen. Schmerz. 2014;28(3):265-81.

11. Helander EM, Eskander JP, Juneau CL, Novitch MB, Prabhakar A, DeKerlegand AM, Cornett EM, and Kaye AD. Preemptive Analgesia, Regional Anesthesia, and Prevention of Chronic Postoperative Pain. Essentials Reg Anesth. 2018;445-62.

12. Hanna M, Moon JY. A review of dexketoprofen trometamol in acute pain. Current medical research and opinion. 2019;35(2):189-202.

13. Jain S, Kalra S, Sharma B, Sahai C, Sood J. Evaluation of Ultrasound - Guided Transversus Abdominis Plane Block for Postoperative Analgesia in Patients Undergoing Intraperitoneal Onlay Mesh Repair. Anesth Essays Res. 2019;13(1):126-31.

14. Salman AE, Yetişir F, Yürekli B, Aksoy M, Yildirim M, and Kiliç $M$. The effıcacy of the semi-blind approach of transversus abdominis plane block on postoperative analgesia in patients undergoing inguinal hernia repair: a prospective randomized double-blind study. Local and regional anesthesia. 2013;6:1-7.

15. Kendigelen P, Tutuncu AC, Erbabacan E, Ekici B, Köksal G, Altindas F, Kaya G. Ultrasound-assisted transversus abdominis plane block vs wound infiltration in pediatric patient with inguinal hernia: Randomized controlled trial. J Clin Anesth. 2016;30:9-14.

16. Talib MT, Sikander RI, Ahsan MF. Ultrasound guided transversus abdominis plane ( TAP ) block is better than local wound infiltration for postoperative pain management in inguinal hernia repair. Anaesthesia, Paın \& Intensive Care. 2015;19(4):457-62.

17. Ma N, Duncan JK, Scarfe AJ, Schuhmann S, Cameron AL. Clinical safety and effectiveness of transversus abdominis plane (TAP) block in post-operative analgesia: a systematic review and metaanalysis. J Anesth. 2017;31(3):432-52.

18. Long JB, Bevil K, Giles DL. Preemptive Analgesia in Minimally Invasive Gynecologic Surgery. J Minim Invasive Gynecol. 2019;26(2):198-218. 
19. Theodoraki K, Papacharalampous P, Tsaroucha A, Vezakis A, Argyra E. The effect of transversus abdominis plane block on acute and chronic pain after inguinal hernia repair. A randomized controlled trial. International Journal of Surgery. 2019;63:63-70.

20. Venkatraman R, Abhinaya RJ, Sakthivel A, Sivarajan G. Efficacy of ultrasound-guided transversus abdominis plane block for postoperative analgesia in patients undergoing inguinal hernia repair. Local Reg Anesth. 2016;9:7-12.

21. Yucel E, Kol IO, Duger C, Kaygusuz K, Gursoy S, Mimaroglu C. Ilioinguinal-iliohypogastric nerve block within travenous dexketoprofen improves postoperative analgesia in abdominal hysterectomies. Rev Bras Anestesiol. 2013;63(4):334-9.

\section{Tables}

Table 1. Demographic data and clinical characteristics

\begin{tabular}{|c|c|c|c|c|}
\hline & $\begin{array}{c}\text { Group1 }(\mathrm{n}=40) \\
\text { Mean } \pm \mathrm{SD}^{*}\end{array}$ & $\begin{array}{l}\text { Group2(n=40) } \\
\text { Mean } \pm \text { SD }\end{array}$ & $\begin{array}{c}\text { Group3(n=40) } \\
\text { Mean } \pm \text { SD }\end{array}$ & $p$ value \\
\hline Age (years) & $46.73 \pm 15.05$ & $48.68 \pm 15.10$ & $51.48 \pm 16.23$ & 0.389 \\
\hline Size $(\mathrm{cm})$ & $173.05 \pm 6.11$ & $173.30 \pm 6.32$ & $173.83 \pm 4.16$ & 0.821 \\
\hline Weight (kg) & $73.35 \pm 8.67$ & $72.13 \pm 10.79$ & $74.50 \pm 7.50$ & 0.507 \\
\hline $\mathrm{BMI}^{* *}$ & $24.45 \pm 2.30$ & $23.89 \pm 2.25$ & $24.65 \pm 2.38$ & 0.308 \\
\hline Gender (Male / Female) & $38 / 2$ & $39 / 1$ & $36 / 4$ & 0.346 \\
\hline Surgical time (minutes) & $58.88 \pm 18.75$ & $56.38 \pm 14.89$ & $53.25 \pm 17.30$ & 0.339 \\
\hline Surgical Region & & & & 0.058 \\
\hline Right & 22 & 21 & 20 & \\
\hline Left & 14 & 16 & 20 & 0.295 \\
\hline Bilateral & 4 & 3 & 0 & \\
\hline
\end{tabular}

*Standart Deviation: ${ }^{* *}$ Body Mass Index

Table 2. Rescue analgesic requirement, opioid consumption and complication rates 


\begin{tabular}{lcccc}
\hline & $\begin{array}{c}\text { Group1 } \\
(\mathrm{n}=40)\end{array}$ & $\begin{array}{c}\text { Group2 } \\
(\mathrm{n}=\mathbf{4 0 )}\end{array}$ & $\begin{array}{c}\text { Group3 } \\
(\mathrm{n}=\mathbf{4 0})\end{array}$ & p value \\
\hline Number of patients in need of rescue analgesics (\%) & $6(15)$ & $6(15)$ & $8(20)$ & 0.787 \\
Opioid consumption (average mg / kg) & 22.5 & 20 & 27.5 & 0.833 \\
Total amount of opioids used (mg) & 900 & 800 & 1100 & 0.451 \\
Postoperative analgesia duration (hours) & 21.0 & 21.2 & 21.4 & 0.960 \\
Complication (PONV*+globe vesicale) & $6(\% 15)$ & $0(\% 0)$ & $2(\% 5)$ & $0.024^{* *}$ \\
\hline
\end{tabular}

* Postoperative nause-vomiting; ** statistically significant

Table 3. Visual analog scale values and rescue opioid doses

\begin{tabular}{|c|c|c|c|c|c|}
\hline \multirow[t]{2}{*}{ Group } & \multirow[t]{2}{*}{ VAS* } & \multicolumn{3}{|c|}{ The amount of rescue tramadol } & \multirow[t]{2}{*}{ Total } \\
\hline & & 0 & $0-100 \mathrm{mg}$ & $100-300 \mathrm{mg}$ & \\
\hline \multirow{4}{*}{ Group 1} & $\leq 3$ (mild) & 34 & 0 & 0 & $34(\% 85)$ \\
\hline & 4-6(moderate) & 0 & 3 & 3 & $6(\% 15)$ \\
\hline & 7-10(severe) & 0 & 0 & 0 & 0 \\
\hline & Total & \multicolumn{3}{|c|}{40} & $40(\% 100)$ \\
\hline \multirow{4}{*}{ Group 2} & $\leq 3($ mild $)$ & 34 & 0 & 0 & $34(\% 85)$ \\
\hline & 4-6(moderate) & 0 & 4 & 2 & $6(\% 15)$ \\
\hline & 7-10(severe) & 0 & 0 & 0 & 0 \\
\hline & Toplam & \multicolumn{3}{|c|}{40} & $40(\% 100)$ \\
\hline \multirow{4}{*}{ Group 3} & $\leq 3($ mild $)$ & 32 & 0 & 0 & $32(\% 80)$ \\
\hline & 4-6(moderate) & 0 & 5 & 3 & $8(\% 20)$ \\
\hline & 7-10(severe) & 0 & 0 & 0 & 0 \\
\hline & Total & \multicolumn{3}{|c|}{40} & $40(\% 100)$ \\
\hline
\end{tabular}

* Visual analog scale

Table 4. Mean Visual analogue scale values [Mean (min - max)] 


\begin{tabular}{|c|c|c|c|c|c|c|c|}
\hline & $\begin{array}{c}\text { Group } 1 \\
(\mathrm{n}=40)\end{array}$ & $\begin{array}{l}\text { Group2 } \\
(\mathrm{n}=40)\end{array}$ & $\begin{array}{l}\text { Group3 } \\
(\mathrm{n}=40)\end{array}$ & $\underset{\text { değeri }}{\mathbf{p}}$ & $\begin{array}{c}\text { Post- } \\
\text { hoc } \\
\text { p } \\
\text { (Group } \\
1 \text { ve 2) }\end{array}$ & $\begin{array}{l}\text { Post-hoc p } \\
\text { (Group } 1 \text { ve } \\
3 \text { ) }\end{array}$ & $\begin{array}{l}\text { Post-hoc p } \\
\text { (Group } 2 \text { ve } \\
3 \text { ) }\end{array}$ \\
\hline 30.minute & $0.38(0-4)$ & $\begin{array}{c}0.90(0- \\
3)\end{array}$ & $\begin{array}{c}1.13(0- \\
4)\end{array}$ & 0.003* & 0.049* & $0.003^{*}$ & 0.564 \\
\hline 1.hour & $0.43(0-4)$ & $\begin{array}{c}0.90(0- \\
3)\end{array}$ & $\begin{array}{c}1.10(0- \\
4)\end{array}$ & 0.007* & 0.072 & $0.006^{*}$ & 0.619 \\
\hline 2.hour & $0.93(0-4)$ & $\begin{array}{c}1.50(0- \\
4)\end{array}$ & $\begin{array}{c}1.55(0- \\
3)\end{array}$ & 0.013* & $0.037 *$ & $0.021 *$ & 0.974 \\
\hline 4.hour & $1.28(0-4)$ & $\begin{array}{c}1.80(0- \\
4)\end{array}$ & $\begin{array}{c}1.90(0- \\
6)\end{array}$ & 0.049* & 0.130 & 0.057 & 0.927 \\
\hline 8.hour & $1.15(0-6)$ & $\begin{array}{c}1.80(0- \\
6)\end{array}$ & $\begin{array}{c}1.95(0- \\
6)\end{array}$ & $0.015^{*}$ & 0.065 & $0.017 *$ & 0.861 \\
\hline 12.hour & $1.08(0-5)$ & $\begin{array}{c}1.53(0- \\
4)\end{array}$ & $\begin{array}{c}1.83(0- \\
6)\end{array}$ & $0.021 *$ & 0.215 & $0.016^{*}$ & 0.501 \\
\hline 16.hour & $1.23(0-6)$ & $\begin{array}{c}1.20(0- \\
6)\end{array}$ & $\begin{array}{c}1.60(0- \\
4)\end{array}$ & 0.285 & 0.996 & 0.379 & 0.333 \\
\hline 24.hour & $1.23(0-6)$ & $\begin{array}{c}0.98(0- \\
4)\end{array}$ & $\begin{array}{c}1.58(0- \\
4)\end{array}$ & 0.069 & 0.598 & 0.367 & 0.056 \\
\hline Average & 0.95 & 1.32 & 1.57 & & & & \\
\hline
\end{tabular}

* statistically significant

Figures 


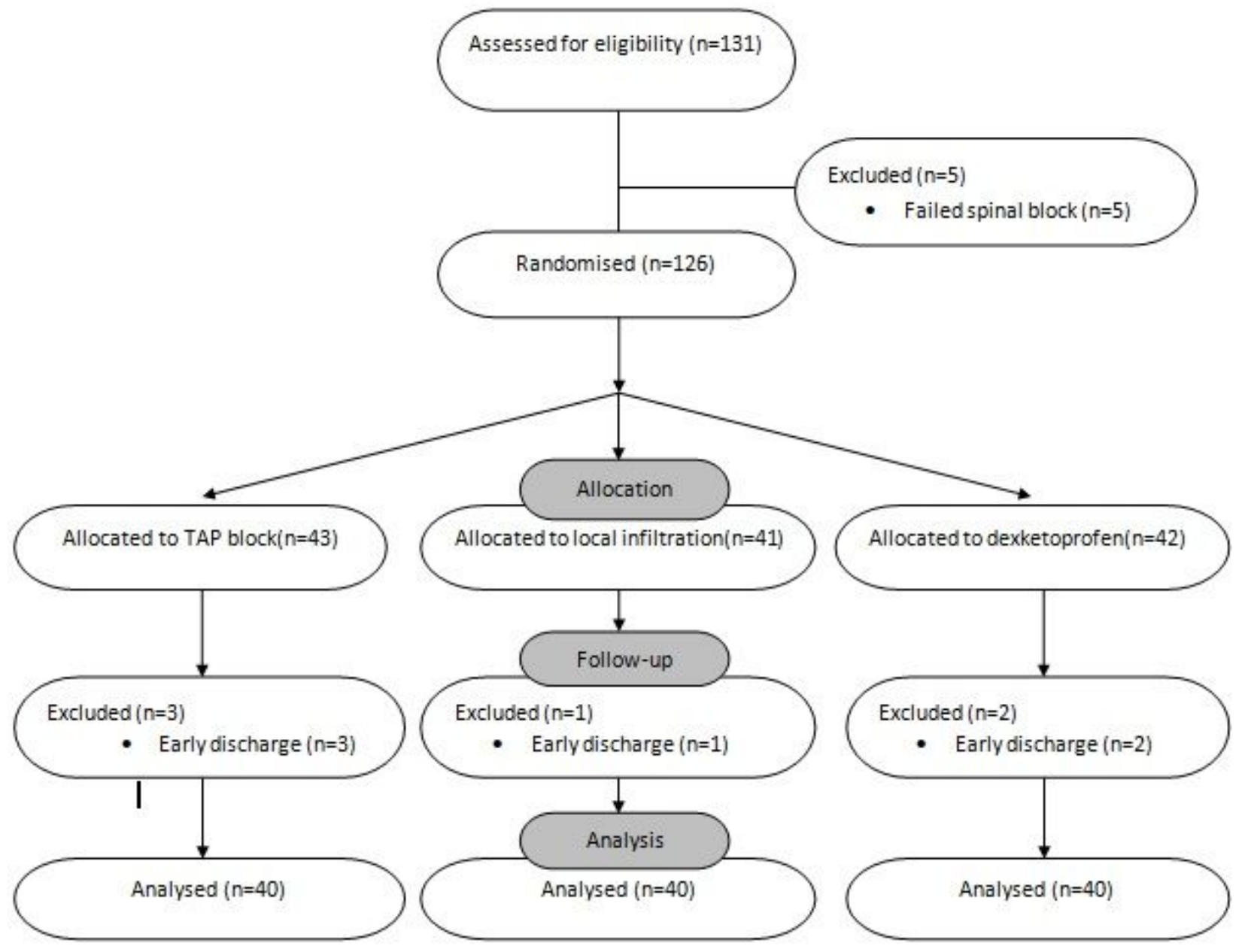

Figure 1

Flow chart 


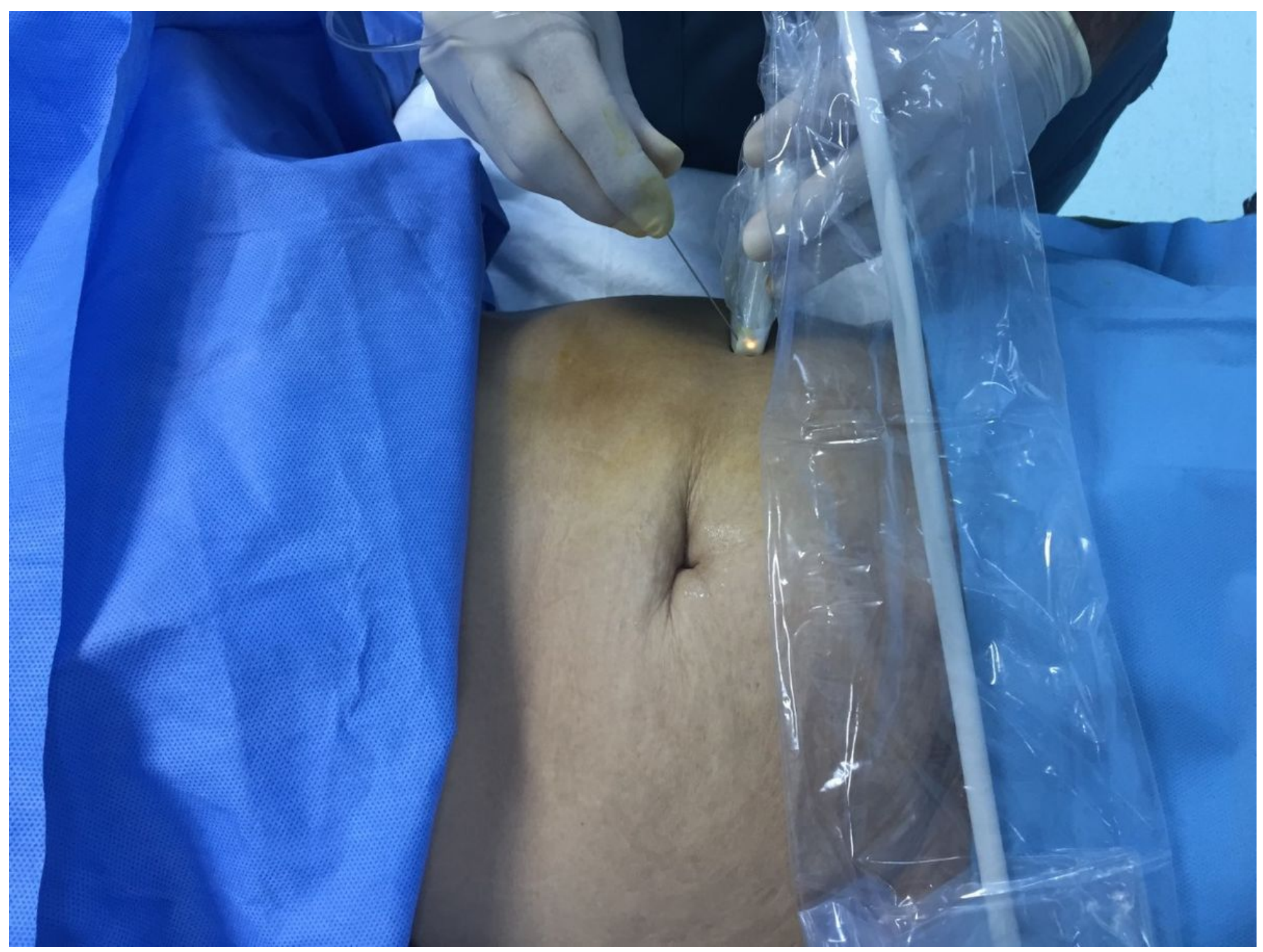

Figure 2

Probe position 


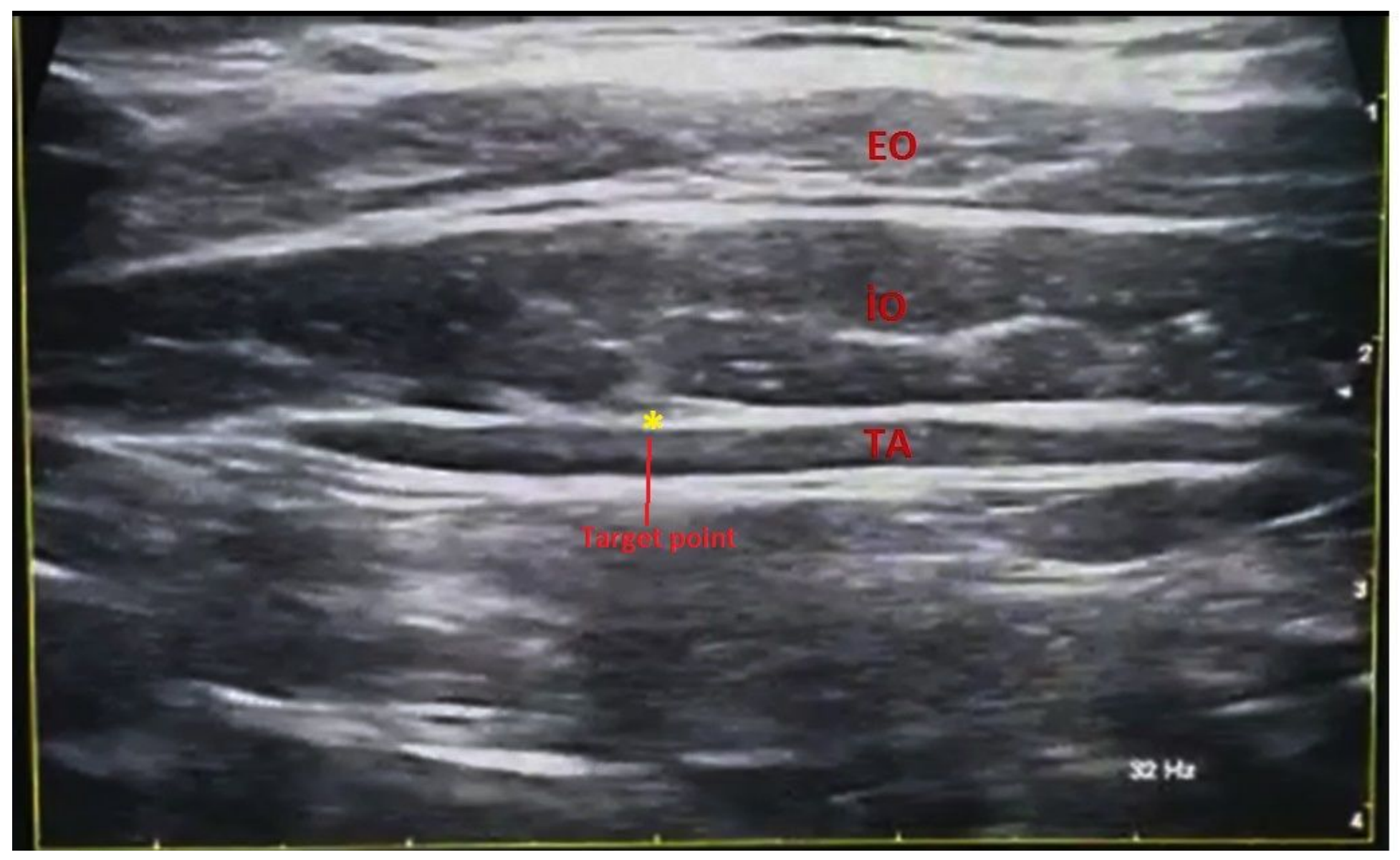

Figure 3

Before block. EO: External Oblique. IO: Internal Oblique. TA: Transversus Abdominis. 


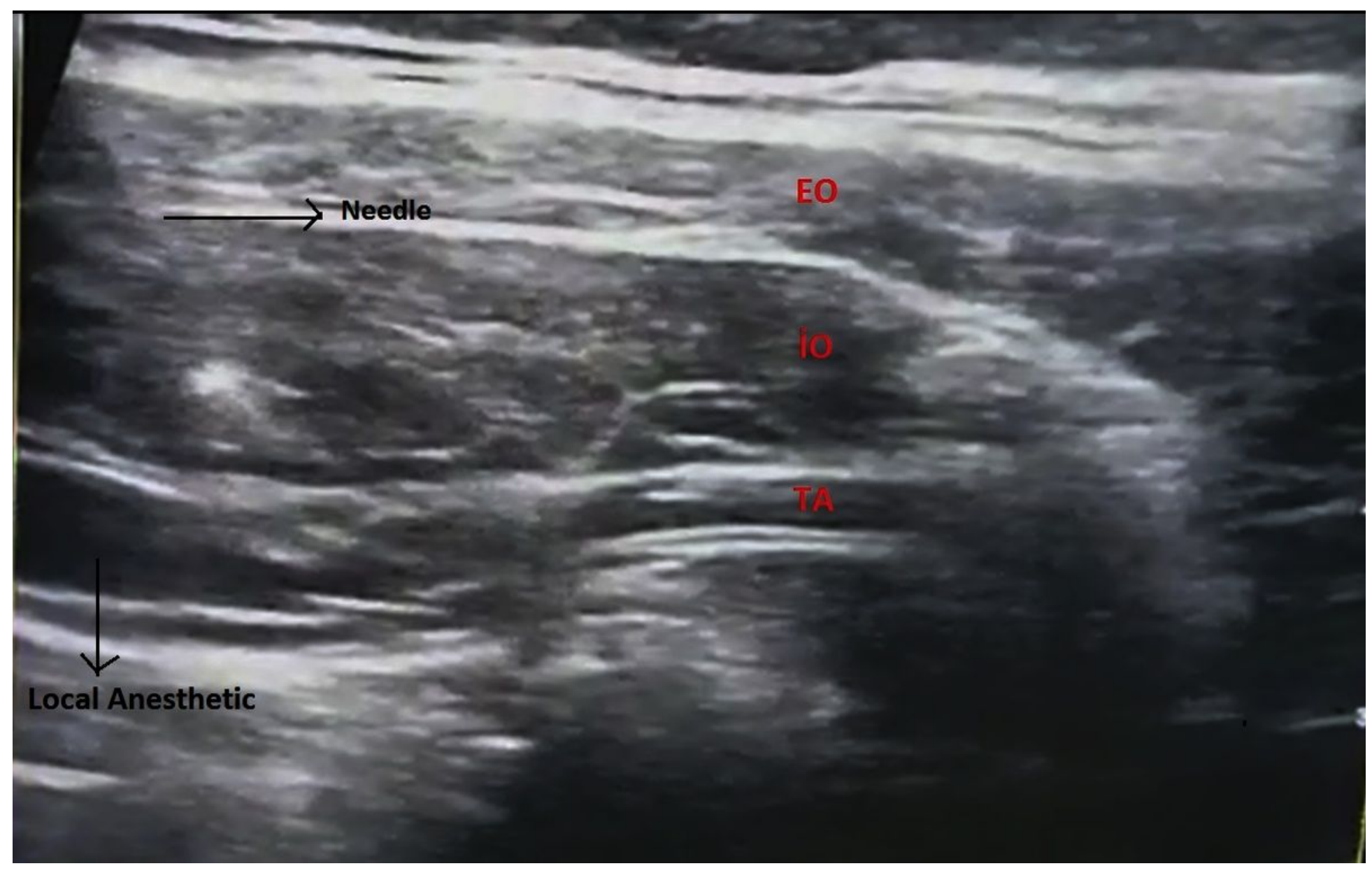

Figure 4

After block. EO: External Oblique. IO: Internal Oblique. TA: Transversus Abdominis. 

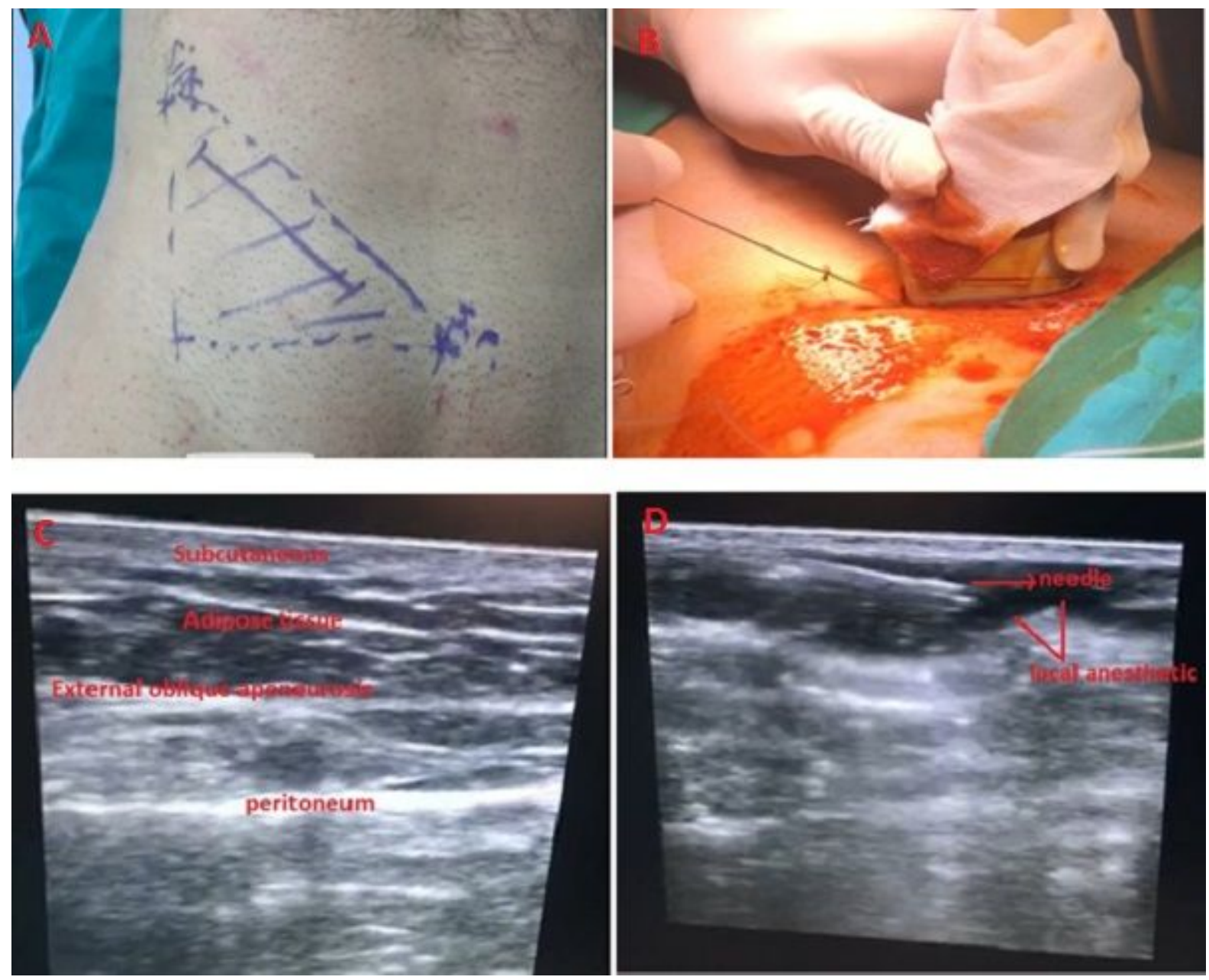

\section{Figure 5}

A: Pre-marked by the surgeon before LAI. B: Probe position. C: Visualization of inguinal region with USG before LAI. D: After block and distribution of local anesthetic. 


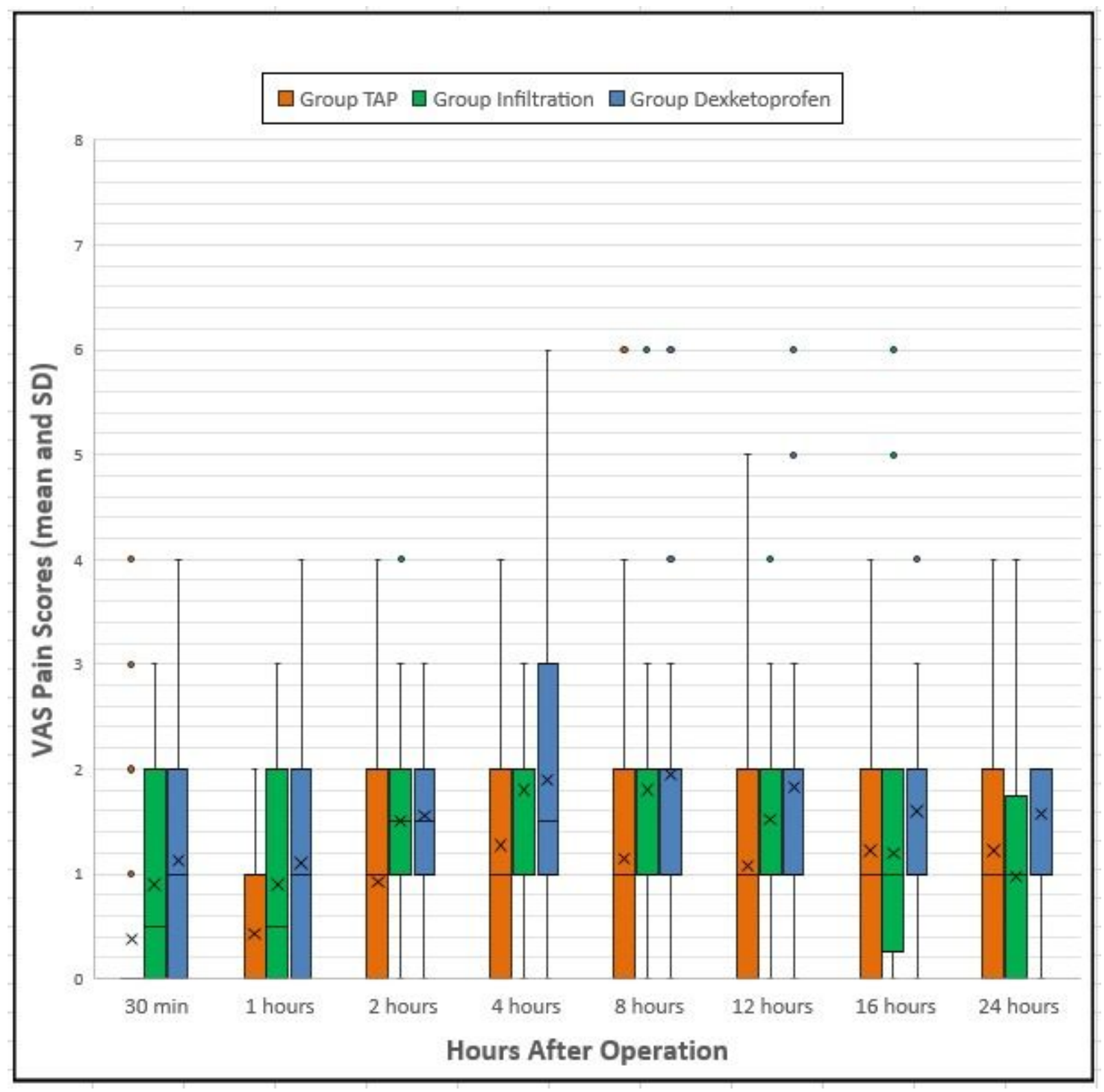

Figure 6

Postoperative visual analog scale scores in all groups. Postoperative visual analog scale scores of patients in 30th minute, 1., 2., 4., 8., 12., 16. and 24. hours after operation in all groups. VAS: Visual analog scale; TAP: Transversus abdominis plane.

\section{Supplementary Files}

This is a list of supplementary files associated with this preprint. Click to download.

- CONSORTChecklist.docx 